\title{
De novo prediction of cross-effect efficiency for magic angle spinning dynamic nuclear polarization
}

\author{
Frédéric Mentink-Vigier ${ }^{a, b}$, Anne -Laure Barra ${ }^{c}$, Johan van Tol $^{b}$, Sabine Hediger ${ }^{a}$, Daniel \\ Lee $^{a}$, and Gaël De Paëpe ${ }^{a}$ \\ aUniv. Grenoble Alpes, CEA, CNRS, INAC-MEM, F-38000 Grenoble, France. \\ bNational High Magnetic Field Laboratory, Tallahassee, FL, 32301, USA \\ 'Laboratoire National des Champs Magnétiques Intenses - CNRS, Univ. Grenoble Alpes, \\ F-38042 Grenoble, France
}

\section{Abstract}

\begin{abstract}
Magic angle spinning dynamic nuclear polarization (MAS-DNP) has become a key approach to boost the intrinsic low sensitivity of NMR in solids. This method relies on the use of both stable radicals as polarizing agents (PAs) and suitable high frequency microwave irradiation to hyperpolarize nuclei of interest. Relating PA chemical structure to DNP efficiency has been, and is still, a long-standing problem. The complexity of the polarization transfer mechanism has so far limited the impact of analytical derivation. However, recent numerical approaches have profoundly improved the basic understanding of the phenomenon and have now evolved to a point where they can be used to help design new PAs. In this work, the potential of advanced MAS-DNP simulations combined with DFT calculations and high-field EPR to qualitatively and quantitatively predict hyperpolarization efficiency of particular PAs is analyzed. This approach is demonstrated on AMUPol and TEKPol, two widely-used bis-nitroxide PAs. The results notably highlight how the PA structure and EPR characteristics affect the detailed shape of the DNP field profile. We also show that refined simulations of this profile using the orientation dependency of the electron spinlattice relaxation times can be used to estimate the microwave $B_{1}$ field experienced by the sample. Finally, we show how modelling the nuclear spin-lattice relaxation times of close and bulk nuclei while accounting for PA concentration allows for a prediction of DNP enhancement factors and hyperpolarization build-up times.
\end{abstract}

\section{Graphical Abstract}

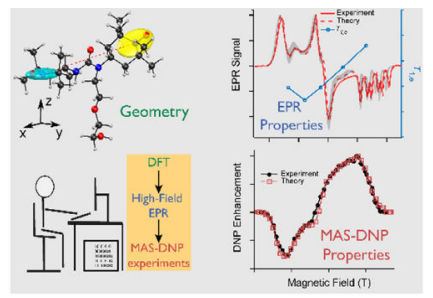


From the polarizing agent geometry and EPR properties to the prediction of magic angle spinning dynamic nuclear polarization efficiency

\section{Keywords}

Dynamic Nuclear Polarization; solid-state NMR; depolarization; MAS-DNP; Theory; High-Field EPR; DFT; Biradicals; Nitroxides

\section{Introduction}

Dynamic nuclear polarization (DNP) attracts large interest because it can provide impressive sensitivity gains to solid-state Nuclear Magnetic Resonance (ssNMR) spectroscopy. In DNP, the large intrinsic polarization of electron spins is transferred to nuclei. While this method was established under static conditions, its extension to spinning samples ${ }^{1-3}$ and high magnetic field (> $5 \mathrm{~T}$ ) combined with high-power, high-frequency microwaves ${ }^{4,5}$ has provided large nuclear hyperpolarization along with high spectral resolution for ssNMR. This has enabled NMR experiments that would have been otherwise impracticable ${ }^{6-14}$.

It was with the introduction of nitroxide biradicals ${ }^{15}$ that the highest Magic Angle Spinning (MAS) NMR sensitivities have been obtained using DNP. Based on the cross-effect (CE) mechanism under MAS, which requires two coupled electron spins and a mutually-coupled nuclear spin, ${ }^{16-18}$ these bis-nitroxides can provide a fast build-up of relatively high nuclear polarization levels. Nowadays, two main categories of bis-nitroxides are being developed, based on different chemical linkers that tether the two nitroxide moieties: the bTbK family (based on a bis-Ketal linker), ${ }^{19}$ and the bTurea family (based on a urea linker). ${ }^{20,21}$ The chemical structures for these families were designed based on empirical approaches that have shown that both the relative orientation of the $g$-tensors of the two electron spins and their inter-spin distance affects the DNP efficiency. ${ }^{19,20,22,23}$ Each family now has several substructures and colossal synthesis and experimental work has been performed to optimize the structures further. ${ }^{23-27}$ These studies notably highlighted that electron relaxation times are key parameters for efficient $\mathrm{DNP},{ }^{22}$ which can be tuned by changing the molecular weight of the radical. ${ }^{28}$ Nowadays, derivatives of the $b^{2} \mathrm{CK}^{25,29}$ and bTurea ${ }^{26,27,30}$ families, in particular TEKPol ${ }^{24}$ and AMUPol, ${ }^{23}$ are commonly used and considered as highlyefficient and versatile polarizing agents (PAs) for CE-DNP.

In parallel to this experimental work, theoretical/numerical analyses have supplied some substantial elements to the understanding of the CE under MAS. ${ }^{16-18,31}$ First, it differs strikingly from the static case as the MAS induces energy level anti-crossings, called rotor events. ${ }^{18,32-35}$ When considering the smallest spin system (2 electrons, one nucleus), there are 4 rotor-event types: microwave ( $\mu \mathrm{w})$, dipolar/J, cross-effect and solid-effect (SE). These occur (predominantly) sequentially at different rotor positions. Each rotor event occurs with a given efficiency that depends on the 3D structure of the PA, the crystal orientation, and the magnitude of the effective coupling at stake during the level anti-crossing as well as the duration of the crossing (that can thus be related to the MAS frequency and the static magnetic field). The size of the nuclear polarization enhancement results from the combination of these events and the relaxation mechanisms. 
So far, the complexity of the MAS-DNP mechanism has severely limited the ability to predict reliably the performance of a given PA. For instance, even if a biradical is modeled by a simple three-spin system ( 2 electron spins and one ${ }^{1} \mathrm{H}$ spin), it already requires determining at least 21 parameters (see SI for details). In addition, the complexity of the modulation induced by the sample spinning has prevented the derivation of an analytical solution. For this reason, the development of numerical simulations ${ }^{16-18,31,33}$ appears as a good strategy to provide insight into the structure-efficiency relationship. ${ }^{18,33,36}$ In addition, since numerical simulations tend to require substantial computation time, there have been recent efforts towards developing a fast and accurate simulation tool, that can be used to scan through the multiple parameters involved in the mechanism. ${ }^{33}$

In this article we demonstrate that this fast simulation tool can be used to predict the performance of a bis-nitroxide. To that purpose, we combined density functional theory (DFT), high-field electron paramagnetic resonance (EPR) and MAS-DNP simulations to predict the behavior of well-known biradicals. The approach is applied to the bTbK and bTurea families, for which we compare simulations and experimental data obtained on the TEKPol and AMUPol biradicals.

\section{Material and methods DNP-sample preparation}

The biradical families used in this study are shown in Figure 1. The TEKPol sample was prepared by dissolution in $\mathrm{CHCl}_{3} / 1,1,1,2$-tetrabromoethane(TBE)/ $\mathrm{D}_{4}-\mathrm{MeOH}(65 / 30 / 5 \mathrm{v} \%)$ to form a $15 \mathrm{mM}$ solution. This solvent mixture was chosen as it forms a relatively good and reproducible glass. The AMUPol sample was prepared by dissolution in a $2 \mathrm{M}^{13} \mathrm{C}$-urea $\mathrm{D}_{8}$ glycerol $/ \mathrm{D}_{2} \mathrm{O} / \mathrm{H}_{2} \mathrm{O}(60 / 30 / 10 \mathrm{v} \%)$ mixture to form a $10 \mathrm{mM}$ solution. For each sample, the experiments have been carried out in $3.2 \mathrm{~mm}$ outer-diameter sapphire MAS rotors.

\section{DFT calculations}

The initial geometrical structures have been obtained using Ghemical v3.0.2 $2^{37}$ and the Tripos 5.2 force field. ${ }^{38}$ Using the random conformation search on a reduced (i.e. protonated) nitroxide, the most energetically-favorable radical conformation was used as the input structure for DFT calculations.

The ORCA program package (v. 3.0.2) ${ }^{39}$ was employed for all electronic structure calculations. All geometry optimizations were performed in two steps: a quick optimization using the LDA functional and Def2-SVP basis set ${ }^{40}$ with the RI approximation, and the resulting structure was then further optimized using the GGA BP86 functional and Def2TZVP basis set. ${ }^{41,42}$ This final structure was then used for the calculations of the $g$-tensors using the B3LYP ${ }^{43-45}$ functional with Def2-TZVP basis. ${ }^{41,42}$ The electron-electron dipolar coupling was obtained in the same way, calculating only the spin-spin contribution with B3LYP and EPR-II basis. ${ }^{46}$ Note that our aim is to obtain the geometry of the biradical and therefore not much effort has been put to compute accurately the $g$-values or the ${ }^{14} \mathrm{~N}$ hyperfine coupling as they depend on the solvent. ${ }^{47,48} \mathrm{In}$ addition, the $J$ exchange interaction in these biradicals is too small to be accurately computed via DFT. 


\section{Experimental setup}

The MAS-DNP properties were measured on a Bruker 9.4 T / 264 GHz DNP-NMR Avance III spectrometer, installed in Grenoble (France), and on a Bruker 14.1 T / $395 \mathrm{GHz}$ DNP system installed in Tallahassee (FL, USA) ${ }^{49}$ operating at proton Larmor frequencies of 400 $\mathrm{MHz}$ and $600 \mathrm{MHz}$, respectively. Both systems are equipped with low-temperature $3.2 \mathrm{~mm}$ wide-bore MAS probes able to spin samples up to $\sim 15 \mathrm{kHz}$ at $\sim 100 \mathrm{~K} .{ }^{50}$ Sample temperature was set to $\sim 110 \mathrm{~K}$ for all experiments, adjusting the sample-cooling gas flow accordingly to account for temperature variations due to different MAS rates and $\mu \mathrm{w}$ irradiation. ${ }^{51}$ The $\mu \mathrm{w}$ power was optimized to give the maximum signal intensity at a MAS frequency of $8 \mathrm{kHz}$. All experiments for a given sample were performed without ejecting the sample to ensure a consistent glass quality. For signal-averaging, a recycle delay of $7 \times{ }^{1 \mathrm{H}} T_{\mathrm{B}}$ was used to ensure a complete return to equilibrium of ${ }^{1} \mathrm{H}$ spins between transients, where $T_{\mathrm{B}}$ is the time constant for polarization build up after saturation. ${ }^{1} \mathrm{H}$ spectra were obtained using a $\pi / 2$ excitation pulse of $100 \mathrm{kHz}$ RF field strength. ${ }^{13} \mathrm{C}$ spectra were measured using $\left\{{ }^{1} \mathrm{H}-\right\}^{13} \mathrm{C}-\mathrm{CP}{ }^{52-54}$ (cross-polarization) with SPINAL-64 ${ }^{55}$ heteronuclear decoupling at 83 $\mathrm{kHz}$ field strength. The DNP field profile of TEKPol and AMUPol were recorded using the optimal $\mu \mathrm{w}$ power for each biradical solution.

The $285 \mathrm{GHz}$ continuous-wave (CW) EPR spectra were recorded at the Laboratoire National des Champs Magnétiques Intenses (LNCMI, Grenoble, France) on a custom-built CW EPR spectrometer. ${ }^{56,57}$ The EPR spectrum was recorded at $100 \mathrm{~K}$, using a microwave irradiation frequency of $285 \mathrm{GHz}$, a field modulation of $\sim 0.4 \mathrm{mT}$ and a sweep rate of $0.30 \mathrm{mT} / \mathrm{s}$.

The $240 \mathrm{GHz}$ CW and pulsed EPR data have been recorded on the 112/240/336 GHz quasioptical spectrometer installed in Tallahassee. ${ }^{58,59}$ The sequences used were either a 2-pulse Hahn echo or for the $T_{1}$ measurements an echo-detected saturation recovery experiment, using pulses of $700 \mathrm{~ns}-\tau-900 \mathrm{~ns}$ for the echo detection and a $1 \mathrm{~ms}$ saturation pulse, respectively. A CW spectrum was also recorded using a modulation of $0.3 \mathrm{mT}$ and $40 \mu \mathrm{W}$ irradiation power with a sweep rate of $0.2 \mathrm{mT} / \mathrm{s}$ at a temperature of $100 \mathrm{~K}$.

\section{Data analysis}

The DNP enhancement $\epsilon_{\mathrm{on} / \mathrm{off}}$, the ratio of the intensities of the NMR signal obtained in presence and absence of $\mu \mathrm{w}$ irradiation can be measured on the ${ }^{13} \mathrm{C}$ signal of urea or chloroform. It was verified that this ratio also corresponds to the enhancement measured directly on the ${ }^{1} \mathrm{H}$ spectrum. The Boltzmann polarization gain $\epsilon_{B}$ and the depolarization, $\epsilon_{\text {Depo }}$, have been quantified using a previously-described method by following the absolute intensity of the integrated ${ }^{1} \mathrm{H}$ signal in presence and absence of $\mu \mathrm{w}$ irradiation. ${ }^{32} \epsilon_{\mathrm{on} / \mathrm{off}}, \epsilon_{\mathrm{B}}$, and $\epsilon_{\text {Depo }}$ are connected by the following relation $\epsilon_{\text {on/off }}=\epsilon_{\mathrm{B}} \times \epsilon_{\text {Depo }}{ }^{32,33}$

\section{EPR and MAS-DNP simulations}

The high-field EPR spectra of TEKPol and AMUPol were fitted using the Easyspin toolbox v.5.1. ${ }^{60}$ The initial electron-electron dipolar tensor and the $g$-tensors relative orientation were obtained from the DFT calculations, whereas the initial principal axis frame values for $g$-tensor and ${ }^{14} \mathrm{~N}$ hyperfine tensor were extracted from the literature. ${ }^{47,48,61,62}$ The line broadening used, corresponding to a $g$-strain equal to $\left[1.3 \times\left(g_{\mathrm{x}}-2\right), g_{\mathrm{y}}-2, g_{\mathrm{z}}-2\right] \times 6 \%$, led to a 
satisfying result. Note that the EPR spectra were computed with the "matrix" method, which relies on the diagonalization of the Hamiltonian.

The MAS-DNP simulations were carried out following the approach described previously $16,18,32$ and using the latest computational implementation. ${ }^{33}$ The spin systems considered in the rest of the manuscript are composed either of a box containing multiple copies of two electrons and one proton $\left\{{ }^{1} \mathrm{H}_{1}-\mathrm{e}_{\mathrm{a}}-\mathrm{e}_{\mathrm{b}}\right\}$ (referred to as the box model) or two electrons linked to $N$ protons (referred to as the multi-nuclei model), as previously described. ${ }^{33}$

The simulations include dipolar and $J$ exchange interactions between the two electrons within a biradical, intermolecular electron-electron dipolar couplings for the box model, as well as the presence of $g$-strain.

The code has been improved for the computation of the $\mu \mathrm{w}$ rotor events: the electron resonant frequencies now include the frequency shift induced by the intramolecular dipolar/ $J$ exchange interaction (see SI for details), in addition to the frequency shift induced by the hyperfine coupling to the ${ }^{14} \mathrm{~N}$ spin present in the nitroxide moieties.

The multi-nuclei model ${ }^{33}$ is composed of 4 strongly hyperfine coupled protons (about 3 MHz of hyperfine coupling each) and 5 layers of protons (corresponding to 220 nuclei with a hyperfine coupling smaller than $3 \mathrm{MHz}$ ). Note that the $3 \mathrm{MHz}$ hyperfine coupling for the closest protons was chosen (except specified otherwise) as an average value and corresponds to protons from the nitroxide moiety and/or from surrounding molecules. ${ }^{63}$ The numerical details can be found in the SI.

Powder averaging is performed using two angles $987 \mathrm{ZCW}$ crystal file. ${ }^{64-66}$ For the boxmodel, ${ }^{33}$ the powder averaging is performed by generating 32 boxes each containing 30 randomly oriented biradicals. Their orientations were chosen from the crystal file such that each crystal orientation can only be selected once. When using the multi-nuclei model, $N=$ 437 and $N=476{ }^{1} \mathrm{H}$ nuclei were considered for TEKPol and AMUPol respectively, and the powder averaging was performed using the $610 \mathrm{ZCW}$ crystal file, which is sufficient for evaluating the final polarization and its corresponding build-up time. Note that two or three angles powder averaging led to identical results.

These simulations where performed assuming a temperature of $100 \mathrm{~K}$ in order to define the Boltzmann equilibrium density matrix and where carried out for two different $\mu \mathrm{w}$ irradiation frequencies: $263.73 \mathrm{GHz}$ and $395.175 \mathrm{GHz}$. The $\mu \mathrm{w}$ frequency is kept fixed when the magnetic field is varied for the simulation of the DNP field profile. In addition, unless otherwise specified, the $\mu$ w Rabi frequency was $\omega_{1} / 2 \pi=0.35 \mathrm{MHz}$.

\section{Determining biradical configuration and EPR parameters in the frozen state using DFT and high-field EPR}

The first step before computing CE MAS-DNP efficiency is to determine relevant input parameters that include the polarizing agent geometry and EPR characteristics. To this end, DFT calculations were conducted on simplified structures mimicking AMUPol and TEKPol. 
In the computed structures, corresponding to bTbK and a modified bTurea ${ }^{21,25,30}$ with a short PEG chain, rings in alpha of the nitroxide function (which are present in TEKPol and AMUPol) were excluded for simplicity but the calculations still provide good approximations of TEKPol and AMUPol structures. The results of the optimized structures are shown in Figure 2. The $g$-tensor orientations are schematically represented with an ovoid using the convention that axis length is proportional to the $\left(g_{i}-2\right)$, while the dipolar coupling is represented by a dashed line. Table 1 details the DFT-calculated $g$-values, dipolar couplings, and their relative orientations in the molecular frame.

These parameters (obtained by DFT) can be combined with ${ }^{14} \mathrm{~N}$ hyperfine couplings reported in the literature $48,61,62$ to compute an EPR spectrum that can be compared to experimental data. This comparison needs to be conducted at high magnetic field ( 8.5 and 10.1 $\mathrm{T}$ in this work) in order to improve the resolution and to allow further refining these parameters by fitting the EPR data. The result of this procedure is presented in Figure 3 for TEKPol and AMUPol.

The agreement between simulation and theory is good for both AMUPol and TEKPol. These two biradicals have very different spectral features in the $g_{x}$ and $g_{z}$ regions, reflecting their different geometrical properties.

Table 1 summarizes and compares the EPR parameters obtained by DFT alone and fits to experiments, refined from the DFT-calculated parameters. The grey overlays in Figure 3 and Figure 4 represent the corresponding errors reported. Our analysis notably provides an electron-electron dipolar coupling of $\sim 30 \mathrm{MHz}$ for TEKPol. which is consistent with the previous work conducted on bTbK. ${ }^{19,61}$ This confirms that biradicals within the bTbK family have almost identical geometrical properties. For AMUPol, the analysis reveals the presence of a dipolar coupling of $\sim 35 \mathrm{MHz}$ and an exchange interaction of magnitude $\sim 15$ $\mathrm{MHz}$, in line with previous predictions of the dipolar coupling ${ }^{23}$ and the liquid-state analysis performed in reference [30]. These values as well as the relative orientations for AMUPol obtained here are in very good agreement with a recent multi-frequency EPR analysis. ${ }^{68}$ The experimental data were fitted using a step-by-step simplex approach, fitting first the $g$ values, then the exchange interaction and finally the relative orientations.

It is important to stress that the parameters obtained using DFT were key for the success of the refinement procedure reported here since it provides a good starting point for both biradicals. This allows finding a satisfying solution using only one EPR frequency, whereas multi-frequency EPR fitting is usually required. ${ }^{68-70}$ We also check the robustness of the fit by varying each parameter around its optimum value. This was used to estimate the associated errors for each of the values shown in Table 1. As a side note, it is interesting that in the AMUPol case, the $a$ and $\gamma$ angles have a strong effect on the EPR lineshape in the low-field region. Finally, we verify the accuracy of the parameters by fitting EPR spectra recorded at lower magnetic field, as shown in Figure 4.

The CW EPR lineshape analysis was complemented by conducting high-frequency pulsed EPR measurements to estimate the electron spin relaxation times as a function of the field position. The results obtained for AMUPol are shown in Figure 4 and are consistent with 
previous work..$^{27,47,62,71}$ The electron spin-lattice relaxation time varies throughout the EPR line, with shorter $T_{1 \mathrm{e}}$ values between the $g_{X}$ and $g_{y}$ component and longer $T_{1 \mathrm{e}}$ values around the $g_{Z}$ component. Contrastingly, the phase memory time was constant throughout the EPR lineshape at $T_{\mathrm{m}}=2.5 \pm 0.5 \mu \mathrm{s}$. The phase memory time for TEKPol was too short to be measured within the capabilities of the EPR setup. Such a short $T_{\mathrm{m}}$ for TEKPol compared to AMUPol could be due to the solvent mixture employed. ${ }^{28,47}$ The $T_{1, \mathrm{e}}$ dependency was then plotted a function of the g-value and fitted via a $2^{\text {nd }}$ order polynomial. The obtained function was later used in the MAS-DNP simulations, to compute the relaxation time for each radical orientation and it was assumed that TEKPol and AMUPol have similar electron spin relaxation times. ${ }^{27,47,62,71}$

\section{On the prediction of MAS-DNP field profiles}

\section{DNP field sweep profiles provide an additional spectral fingerprint for biradicals}

Since AMUPol and TEKPol display different EPR spectra, one should expect that this is also the case for the DNP field profiles, which were measured at 9.4 and $14.1 \mathrm{~T}$ for TEKPol and AMUPol, respectively, and are reported in Figure 5. As expected, not only do their shapes differ significantly, but the ratio between the positive and negative maximum as well: $\sim 0.45$ for TEKPol and $\sim 0.75$ for AMUPol. This highlights the potential of these field profiles to be used as spectral fingerprints for PAs, provided that the effect of the microwave $B_{1}$ field strength is accounted for.

\section{Obtaining the microwave $B_{1}$ field at the sample from accurate simulations of the MAS-DNP field profile}

As shown in detail in previous work, ${ }^{18,33}$ MAS-DNP simulations are sensitive to many intrinsic parameters that define a PA. This includes the $g$-tensors, their relative orientations, the electron spin relaxation times (and their dependency with field, temperature, solvent etc.), the strength of the electron-electron dipolar coupling, as well as the exchange interaction (if present). All these intrinsic variables were determined in the previous section and are used in the following simulations.

MAS-DNP simulations also depend on many external parameters such as the magnetic field, the temperature, the MAS frequency, and the microwave $B_{1}$ field strength at the sample. All of these parameters, except the last one, can be experimentally determined easily. Therefore, the last undetermined variable, the microwave $B_{1}$ field strength, was varied to best fit the simulated MAS-DNP field profile to experimental data, as shown in Figure 5. We obtained a very good fit for both AMUPol and TEKPol, using a microwave Rabi frequency $\omega_{1} / 2 \pi=$ $0.35 \mathrm{MHz}$. Figure 5 clearly demonstrates that the simulations are able to reproduce the overall shape of the DNP field profile, some specific details (shoulders, bumps, etc.) and also the relative ratio between the positive and negative maxima. Note that the microwave field strength has a direct effect on the shape of the DNP field profile (see Figure S1), but not on the relative ratio between the positive and negative maxima.

Notably, this value of the microwave Rabi frequency for a $3.2 \mathrm{~mm}$ probe is consistent with recent reports. ${ }^{72,73}$ For completion, the simulated MAS-DNP field profiles for AMUPol and 
TEKPol at 9.4 and 14.1 T, respectively, are reported in Figure S2. Here we used $\omega_{1} / 2 \pi=$ $0.35 \mathrm{MHz}$ as an optimal value but $0.3 \mathrm{MHz}$ and $0.4 \mathrm{MHz}$ would have led to satisfying fits as well. Introducing a distribution of microwave Rabi frequencies (throughout the sample) ${ }^{72,73}$ may improve the overall quality of the fit but this was not attempted in this work.

\section{Effect of the orientation dependence of the electronic $T_{1, \mathrm{e}}$}

The MAS-DNP field profile changes when accounting for the orientation dependency of the electronic relaxation time $T_{1, \mathrm{e}}$. Interestingly, the overall lineshape is not heavily affected, as opposed to the relative ratio between the two maxima (more details in Figure S3).

It is also important to stress that, within reasonable limits, the nuclear relaxation times (from 0.1 to 10 's of s) and the electron-proton hyperfine couplings ( $<10 \mathrm{MHz})$ have no effect on the DNP field profiles, both for the shape and the relative ratio between positive and negative maxima. Nonetheless, these parameters do have a strong effect on the absolute values that can be reached for the enhancement factor $\left(\varepsilon_{\mathrm{on} / \mathrm{off}}\right.$ or $\left.\varepsilon_{\mathrm{B}}\right)$. A change in these parameters acts as an overall scaling factor for the entire DNP field profile.

\section{Effect of the MAS-induced spectral diffusion on the DNP field profile}

When using the "box" model, ${ }^{33}$ the DNP field profile has identical shape whether intermolecular electron-electron dipolar couplings were considered or not. In other words, for realistic PA concentrations $(<20 \mathrm{mM})$, inter-PA electron spin interactions are not large enough to directly perturb the MAS-DNP field profile, although they can have other effects (such as reduced electron spin relaxation times, ${ }^{74}$ which can modify the field profile (vide supra) and increase nuclear depolarization). ${ }^{33}$

\section{Predicting DNP field profiles with simulations}

We have shown in the previous paragraphs that the DNP field profile acts as a spectral fingerprint that encodes the PA's properties (EPR parameters including the hyperfine coupling to the ${ }^{14} \mathrm{~N}$ spin but excluding the hyperfine coupling to the ${ }^{1} \mathrm{H}$ spins) and the microwave $B_{1}$ field strength. We note that for the PAs considered in this work, it was not necessary to consider the presence of a conformational distribution in the frozen solvent matrix. Although this could possibly improve further the quality of the fit reported, it was not attempted in this work. Unavoidably, the use of more flexible linkers could imply the introduction of parameter distributions, such as the relative orientation between the $g$ tensors, the distance between the two electrons or the $J$ exchange interaction. ${ }^{27}$ This was clearly evidenced in our recent work on the biradical TEMTriPol- $1^{35}$ and must therefore be accounted for to obtain accurate simulations.

\section{On the prediction of DNP polarization gain and build-up time}

To test further the predictive capabilities of the simulation tool, we performed calculations using two models, introduced in our previous work. ${ }^{33}$ These two models enable probing specifically various aspects of the DNP mechanism and the results and the comparisons to experimental data are given in Table 2. The first model, called "multi-nuclei", enables the calculation of 2 electrons and $N \geq 1$ protons. It provides a method to account for the impact of 
multiple nuclei on the gain, the depolarization and more importantly on the nuclear polarization build-up time ( $\left.T_{\mathrm{B}}\right)$. The second model, called the "box" model, allows computing a large number of identical three-spin systems ( 2 electrons and 1 proton) in interaction. This enables probing the effect of PA's concentration by including the "MAS induced" spectral diffusion generated by neighbouring biradicals.

\section{The multi-nuclei model}

The "multi-nuclei" model, is designed to match the experimental proton density and the relative ratio between biradical and protons (see Table 2). More specifically, two types of protons are considered, local and bulk. Only the local protons have a hyperfine coupling (always greater than the MAS frequency). For all nuclei we assume that nuclear spin-lattice relaxation time depends on the hyperfine coupling strength. ${ }^{75}$ For a given nucleus $i$, it can be written:

$$
\frac{1}{\boldsymbol{T}_{1, i}^{n}}=\frac{1}{\boldsymbol{T}_{1,1}^{n}}\left(\frac{\boldsymbol{A}_{a, 1}}{\boldsymbol{A}_{a, i}}\right)^{2}+\frac{1}{\boldsymbol{T}_{1, \mathrm{Bulk}}^{n}}
$$

where $T_{1,1}^{\mathrm{n}}$ represents the nuclear spin-lattice relaxation time of the closest (most strongly coupled) proton and $T_{1, \text { Bulk }}^{\mathrm{n}}$ the nuclear spin-lattice relaxation time measured in absence of doping. $A_{a, 1}$ and $A_{a, i}$ represent the hyperfine coupling between the electron and the $I^{\text {th }}$ proton. More details can be found in refs $[33,75]$.

\section{Adjusting the nuclear relaxation time of strongly coupled protons}

$T_{1, \text { Bulk }}^{\mathrm{n}}$ was measured for glycerol- $\mathrm{D}_{8} / \mathrm{D}_{2} \mathrm{O} / \mathrm{H}_{2} \mathrm{O}(6 / 3 / 1 \mathrm{v} \%)$ and $\mathrm{CHCl}_{3} / \mathrm{TBE} / \mathrm{MeOH}-\mathrm{D}_{4}$ $(65 / 35 / 5 \mathrm{v} \%)$ at $9.4 \mathrm{~T}$ and $\sim 110 \mathrm{~K}$ in absence of radical doping. The saturation-recovery build-up curve was fitted to a mono-exponential, and $T_{1 \text {, Bulk }}^{\mathrm{n}}$ estimated to $65 \mathrm{~s}$ and $5.6 \mathrm{~s}$ for the aqueous and organic solvent matrices, respectively. At this point, there is one parameter that has not been evaluated yet, the nuclear spin-lattice relaxation time of the closest proton, $T_{1,1}^{\mathrm{n}}$, since this is very challenging to determine experimentally. ${ }^{76}$ Consequently, the spinlattice relaxation time used in the simulations for the closest proton, $T_{1,1}^{\mathrm{n}}$, was determined by fitting the sum of the simulated build-up curves (over all the protons), to match the experimental polarization build-up time $\left(T_{\mathrm{B}}\right)$, both in the AMUPol and TEKPol case. Significantly, $T_{1,1}^{\mathrm{n}}$ is extracted at around $0.1 \mathrm{~s}$ in both cases, even if $T_{1, \text { Bulk }}^{\mathrm{n}}$ and $T_{\mathrm{B}}$ are substantially different for $10 \mathrm{mM}$ AMUPol in glycerol- $\mathrm{D}_{8} / \mathrm{D}_{2} \mathrm{O} / \mathrm{H}_{2} \mathrm{O}(6 / 3 / 1 \mathrm{v} \%)$ and for 15 $\mathrm{mM}$ TEKPol in $\mathrm{CHCl}_{3} / \mathrm{TBE} / \mathrm{MeOH}-\mathrm{D}_{4}(65 / 35 / 5 \mathrm{v} \%)$. The validity of this result is supported by the fact that the average distance to the closest proton is of the same order of magnitude in both AMUPol and TEKPol. 


\section{Simulating DNP efficiency without accounting for spectral spin diffusion and intermolecular CE}

Using $T_{1,1}^{\mathrm{n}}=0.1 \mathrm{~s}$ for both AMUPol and TEKPol, we can use Equation 1 to calculate $T_{1, i}^{\mathrm{n}}$ for all the other protons, and then compute, using the multi-nuclei model, the DNP enhancement factors $\left(\epsilon_{B}, \epsilon_{\mathrm{on} / \mathrm{off}}\right)$, the depolarization factor $\left(\epsilon_{\mathrm{depo}}\right)$ and the build-up time $\left(T_{\mathrm{B}}\right)$ for $10 \mathrm{mM}$ AMUPol in glycerol- $\mathrm{D}_{8} / \mathrm{D}_{2} \mathrm{O} / \mathrm{H}_{2} \mathrm{O}(6 / 3 / 1 \mathrm{v} \%)$ and for $15 \mathrm{mM}$ TEKPol in $\mathrm{CHCl}_{3} / \mathrm{TBE} / \mathrm{MeOH}-\mathrm{D}_{4}(65 / 35 / 5 \mathrm{v} \%)$. The simulation results can be found in Table 2 and are compared to experimental values. Systematically, the multi-nuclei model overestimates the DNP enhancement factor and underestimates the depolarization effect. Nevertheless, the relative trends are consistent with the experimental data.

AMUPol and TEKPol are two examples of very different situations. For $10 \mathrm{mM}$ AMUPol in glycerol- $\mathrm{D}_{8} / \mathrm{D}_{2} \mathrm{O} / \mathrm{H}_{2} \mathrm{O}(6 / 3 / 1 \mathrm{v} \%)$, the DNP build-up time is $~ 2.9 \mathrm{~s}$ at $9.4 \mathrm{~T}, 100 \mathrm{~K}$, and with a MAS frequency of $8 \mathrm{kHz}$. Since the nuclear spin lattice relaxation time in absence of radical doping is one order of magnitude longer, one can safely conclude that the nuclear spin-lattice relaxation time is not the limiting factor in this case. This can be highlighted by verifying that when $T_{1, \text { Bulk }}^{\mathrm{n}} \geq 20 \mathrm{~s}$, it has minimal effect on the DNP enhancement factor and build-up time (see Figure S5a). However, with $15 \mathrm{mM}$ TEKPol in $\mathrm{CHCl}_{3} / \mathrm{TBE} / \mathrm{MeOH}-\mathrm{D}_{4}$ $(65 / 35 / 5 \mathrm{v} \%)$, the DNP build-up time is similar to the nuclear spin-lattice relaxation in absence of doping ( $2.8 \mathrm{~s}$ and $5.6 \mathrm{~s}$, respectively, at $9.4 \mathrm{~T}, 100 \mathrm{~K}$, and with a MAS frequency of $8 \mathrm{kHz}$ ). The shorter $T_{1 \text {, Bulk }}^{\mathrm{n}}$ in this case limits the overall DNP efficiency (as illustrated in Figure S5b). This is in agreement with previous theoretical predictions described in ref [33].

\section{Using the box model to estimate the effect of electron spectral diffusion}

Although the results presented in the previous paragraph (based on the multi-nuclei model) seem encouraging, there is still much room for improvement in the modelling of the DNP mechanism, especially to mimic the MAS-induced spectral diffusion (via the electronelectron intermolecular dipolar rotor events) and the contribution to the $\mathrm{CE}$ from the intermolecular electron-nuclei couplings. In other words, the multi-nuclei model does not account for the effect of the PA concentration on the DNP mechanism. A model that could account for both PA concentration and a realistic nuclear spin density is still to be developed, and beyond the scope of this article.

One can try to correct the values obtained by the multi-nuclei model to account for the presence of multi-electrons ("box model"). To that end, we propose to use the simplified three-spin system in a box (multiple copies of two electrons and one proton) and to estimate the impact of the presence of intermolecular dipolar interactions on the DNP efficiency. For this, we compute $\epsilon_{B}, \epsilon_{\mathrm{Depo}}$, and $\epsilon_{\mathrm{on} / \mathrm{off}}$, either considering the presence of intermolecular interactions or not, in order to obtain a correction factor defined as follows:

$$
R_{n}=\frac{\epsilon_{n}^{\text {box model }}}{\epsilon_{n}^{3 \text { spins model }}}
$$


where $n=\mathrm{B}$ or Depo or On/Off.

The correction factors $R_{\mathrm{B}} / R_{\text {Depo }} / R_{\text {On/Off }}$ obtained are $0.55 / 0.58 / 0.95,0.57 / 0.7 / 0.82$ and $0.55 / 0.67 / 0.81$ for $10 \mathrm{mM}$ AMUPol in glycerol- $\mathrm{D}_{8} / \mathrm{D}_{2} \mathrm{O} / \mathrm{H}_{2} \mathrm{O}(6 / 3 / 1 \mathrm{v} \%)$ at 9.4 and $14.1 \mathrm{~T}$, and $15 \mathrm{mM}$ TEKPol in $\mathrm{CHCl}_{3} / \mathrm{TBE} / \mathrm{MeOH}-\mathrm{D}_{4}(65 / 35 / 5 \mathrm{v} \%)$ at $9.4 \mathrm{~T}$ respectively. These factors were used to correct the multi-nuclei model and account for the electron concentration effect. The results are shown in Table 2 and are comparable with the experimental values, highlighting that indeed the inter-PA interactions need to be accounted for to obtain better agreement with experiment.

\section{Conclusions}

In this work we have shown that MAS-DNP simulations allow reproducing bis-nitroxide DNP field profiles very accurately given that the radical structure and the EPR properties can be determined. This was demonstrated on AMUPol and TEKPol for which DFT and high-field EPR measurements were combined to obtain the $g$-tensors, their relative orientations, the electron-electron dipolar coupling, as well as the $J$ exchange interaction.

This work highlights DFT's prediction capabilities for biradical's structure. It clearly confirms the presence of an exchange interaction of $\sim 15 \mathrm{MHz}$ and a dipolar coupling of $\sim 35$ MHz for AMUPol, as initially reported, ${ }^{23,30}$ although it was a matter of debate ${ }^{78}$ until recently. ${ }^{68}$ For TEKPol, we estimate the dipolar interaction to $30 \mathrm{MHz}$ while the $J$ exchange interaction is negligible in the bTbK family.

In addition, pulsed high-field EPR measurements were performed at $240 \mathrm{GHz}$, which confirm the orientation dependence of the electron longitudinal relaxation time $T_{1, \mathrm{e}}$ in the 300 to $900 \mu$ s range as previously observed ${ }^{27,62}$ and the short and flat dependency of the phase memory time $T_{\mathrm{m}}$ (estimated to $2.5 \mu$ s throughout the EPR line). We also prove in this work the critical impact of the $T_{1 \mathrm{e}}$ orientation dependence to reproduce the relative ratio between the positive and negative maxima of the DNP field profile. Moreover, we show how the microwave $B_{1}$ field strength $\omega_{1} / 2 \pi$, expected in the 0.1 to $1 \mathrm{MHz}$ range, can be refined to $\sim 0.35 \mathrm{MHz}$ for our experimental setups by simulating the detailed shape of the DNP field profile. This is consistent with recent estimates extracted from high-frequency structural simulator calculations. ${ }^{72,73}$

To further push the boundaries of the prediction capabilities, we used the previously developed "multi-nuclei" model to simulate compute $\epsilon_{B}, \epsilon_{\text {Depo }}, \epsilon_{\mathrm{on} / \mathrm{off}}$, and the corresponding polarization build-up times. The spin-lattice relaxation times of bulk protons $T_{1, n}^{\text {Bulk }}$ used in the simulations were estimated by measuring the ${ }^{1} \mathrm{H}$ nuclear spin-lattice relaxation times in absence of PA doping. The ${ }^{1} \mathrm{H}$ spin-lattice relaxation times of nuclei close to the PA (the ones experiencing the largest hyperfine couplings) were adjusted in order to obtain DNP build-up times $T_{\mathrm{B}}$ in agreement with experiments. This gave an estimation of the spin-lattice relaxation time of the closest ${ }^{1} \mathrm{H}$ for both AMUPol and TEKPol at $9.4 \mathrm{~T}$ and $100 \mathrm{~K}$ to be $\sim 0.1 \mathrm{~s}$. Finally, we introduce an approach to correct the $\epsilon_{B}$, $\epsilon_{\text {Depo }}$, $\epsilon_{\text {on/off }}$ values obtained with the "multi-nuclei" model, while accounting for inter-PA effects, which improves the agreement with experiment. 
This work highlights the ability of the MAS-DNP simulations described here to be quasipredictive and further substantiates recent and on-going efforts towards using numerical simulations for in silico PA design.

\section{Supplementary Material}

Refer to Web version on PubMed Central for supplementary material.

\section{Acknowledgements}

FMV thanks Jean-Marie Mouesca and Maciek Witwicki for their help to perform the DFT calculations. This work was supported by the French National Research Agency (ANR-12-BS08-0016-01, ANR-11-LABX-0003-01 and RTB) and the European Research Council (ERC-CoG- 2015, No. 682895), The National High Magnetic Field laboratory (NHMFL) is funded by the National Science Foundation Division of Materials Research (DMR-1157490 and 1644779) and the State of Florida. The DNP system at the NHMFL is funded in part by NIH S10 OD018519 (magnet and console), and NSF CHE-S1229170 (gyrotron).

\section{References}

1. Wind RA, Duijvestijn MJ, van der Lugt C, Manenschijn A and Vriend J, Applications of dynamic nuclear polarization in 13C NMR in solids, Prog. Nucl. Magn. Reson. Spectrosc, 1985, 17, 33-67.

2. Singel DJ, Seidel H, Kendrick RD and Yannoni CS, A spectrometer for EPR, DNP, and multinuclear high-resolution NMR, J. Magn. Reson, 1989, 81, 145-161.

3. Afeworki M, McKay RA and Schaefer J, Selective observation of the interface of heterogeneous polycarbonate/polystyrene blends by dynamic nuclear polarization carbon-13 NMR spectroscopy, Macromolecules, 1992, 25, 4084-4091.

4. Becerra LR, Gerfen GJ, Temkin RJ, Singel DJ and Griffin RG, Dynamic nuclear polarization with a cyclotron resonance maser at 5 T, Phys. Rev. Lett, 1993, 71, 3561-3564. [PubMed: 10055008]

5. Hall DA, Maus DC, Gerfen GJ, Inati SJ, Becerra LR, Dahlquist FW and Griffin RG, Polarizationenhanced NMR spectroscopy of biomolecules in frozen solution., Science, 1997, 276, 930-2. [PubMed: 9139651]

6. Lafon O, Rosay M, Aussenac F, Lu X, Trébosc J, Cristini O, Kinowski C, Touati N, Vezin H and Amoureux JP, Beyond the silica surface by direct silicon-29 dynamic nuclear polarization, Angew. Chemie - Int. Ed, 2011, 50, 8367-8370.

7. Lee D, Hediger S and De Paëpe G, Is solid-state NMR enhanced by dynamic nuclear polarization?, Solid State Nucl. Magn. Reson, 2015, 66-67, 6-20. [PubMed: 25779337]

8. Märker K, Paul S, Fernández-de-Alba C, Lee D, Mouesca J-M, Hediger S and De Paëpe G, Welcoming natural isotopic abundance in solid-state NMR: probing $\pi$-stacking and supramolecular structure of organic nanoassemblies using DNP, Chem. Sci, 2017, 8, 974-987. [PubMed: 28451235]

9. Märker K, Pingret M, Mouesca JM, Gasparutto D, Hediger S and De Paëpe G, A New Tool for NMR Crystallography: Complete 13C/15N Assignment of Organic Molecules at Natural Isotopic Abundance Using DNP-Enhanced Solid-State NMR, J. Am. Chem. Soc, 2015, 137, 13796-13799. [PubMed: 26485326]

10. Lee D, Leroy C, Crevant C, Bonhomme-Coury L, Babonneau F, Laurencin D, Bonhomme C and De Paëpe $\mathrm{G}$, Interfacial $\mathrm{Ca} 2+$ environments in nanocrystalline apatites revealed by dynamic nuclear polarization enhanced 43Ca NMR spectroscopy, Nat. Commun, 2017, 8, 14104. [PubMed: 28128197]

11. Perras FA, Kobayashi T and Pruski M, Natural Abundance 17O DNP Two-Dimensional and Surface Enhanced NMR Spectroscopy, J. Am. Chem. Soc, 2015, 150622115706000.

12. Perras FA, Boteju KC, Slowing II, Sadow AD and Pruski M, Direct 17 O Dynamic Nuclear Polarization of Single-Site Heterogeneous Catalysts, Chem. Commun, 2018, 3-8.

13. Frederick KK, Michaelis VK, Corzilius B, Ong T, Jacavone AC, Griffin RG and Lindquist S, Sensitivity-Enhanced NMR Reveals Alterations in Protein Structure by Cellular Milieus, Cell, 2015, 163, 620-628. [PubMed: 26456111] 
14. Hediger S, Lee D, Mentink-Vigier F and De Paëpe G, MAS-DNP Enhancements: Hyperpolarization, Depolarization, and Absolute Sensitivity, eMagRes, 2018, 7, 1-13.

15. Hu K-N, Yu H, Swager TM and Griffin RG, Dynamic Nuclear Polarization with Biradicals, J. Am. Chem. Soc, 2004, 126, 10844-10845. [PubMed: 15339160]

16. Mentink-Vigier F, Akbey U, Hovav Y, Vega S, Oschkinat H and Feintuch A, Fast passage dynamic nuclear polarization on rotating solids, J. Magn. Reson, 2012, 224, 13-21. [PubMed: 23000976]

17. Thurber KR and Tycko R, Theory for cross effect dynamic nuclear polarization under magic-angle spinning in solid state nuclear magnetic resonance: the importance of level crossings., J. Chem. Phys, 2012, 137, 084508. [PubMed: 22938251]

18. Mentink-Vigier F, Akbey U, Oschkinat H, Vega S and Feintuch A, Theoretical aspects of Magic Angle Spinning - Dynamic Nuclear Polarization, J. Magn. Reson, 2015, 258, 102-120. [PubMed: 26232770]

19. Matsuki Y, Maly T, Ouari O, Karoui H, Le Moigne F, Rizzato E, Lyubenova S, Herzfeld J, Prisner TF, Tordo P and Griffin RG, Dynamic Nuclear Polarization with a Rigid Biradical, Angew. Chemie Int. Ed, 2009, 48, 4996-5000.

20. Song C, Hu K-N, Joo C-GG, Swager TM and Griffin RG, TOTAPOL: A Biradical Polarizing Agent for Dynamic Nuclear Polarization Experiments in Aqueous Media, J. Am. Chem. Soc, 2006, 128, 11385-11390. [PubMed: 16939261]

21. Ysacco C, Rizzato E, Virolleaud MA, Karoui H, Rockenbauer A, Le Moigne F, Siri D, Ouari O, Griffin RG and Tordo P, Properties of dinitroxides for use in dynamic nuclear polarization (DNP), Phys. Chem. Chem. Phys, 2010, 12, 5841-5845. [PubMed: 20458376]

22. Zagdoun A, Casano G, Ouari O, Lapadula G, Rossini AJ, Lelli M, Baffert M, Gajan D, Veyre L, Maas WE, Rosay M, Weber RT, Thieuleux C, Coperet C, Lesage A, Tordo P and Emsley L, A Slowly Relaxing Rigid Biradical for Efficient Dynamic Nuclear Polarization Surface-Enhanced NMR Spectroscopy: Expeditious Characterization of Functional Group Manipulation in Hybrid Materials, J. Am. Chem. Soc, 2012, 134, 2284-2291. [PubMed: 22191415]

23. Sauvée C, Rosay M, Casano G, Aussenac F, Weber RT, Ouari O and Tordo P, Highly Efficient, Water-Soluble Polarizing Agents for Dynamic Nuclear Polarization at High Frequency, Angew. Chemie Int. Ed, 2013, 52, 10858-10861.

24. Zagdoun A, Casano G, Ouari O, Schwarzwälder M, Rossini AJ, Aussenac F, Yulikov M, Jeschke G, Copéret C, Lesage A, Tordo P and Emsley L, Large Molecular Weight Nitroxide Biradicals Providing Efficient Dynamic Nuclear Polarization at Temperatures up to $200 \mathrm{~K}$, J. Am. Chem. Soc, 2013, 135, 12790-12797. [PubMed: 23961876]

25. Kubicki DJ, Casano G, Schwarzwälder M, Abel S, Sauvée C, Ganesan K, Yulikov M, Rossini AJ, Jeschke G, Copéret C, Lesage A, Tordo P, Ouari O and Emsley L, Rational design of dinitroxide biradicals for efficient cross-effect dynamic nuclear polarization, Chem. Sci, 2016, 7, 550-558. [PubMed: 29896347]

26. Jagtap AP, Geiger M-A, Stöppler D, Orwick-Rydmark M, Oschkinat H and Sigurdsson ST, bcTol: a highly water-soluble biradical for efficient dynamic nuclear polarization of biomolecules, Chem. Commun, 2016, 52, 7020-7023.

27. Geiger M-A, Jagtap A, Kaushik M, Sun H, Stöppler D, Sigurdsson S, Corzilius B and Oschkinat $\mathrm{H}$, Efficiency of water-soluble nitroxide biradicals for dynamic nuclear polarization in rotating solids at 9.4 T: bcTol-M and cyolyl-TOTAPOL as new polarizing agents, Chem. - A Eur. J, , DOI: 10.1002/chem.201801251.

28. Sato H, Kathirvelu V, Fielding A, Blinco JP, Micallef AS, Bottle SE, Eaton SS and Eaton GR, Impact of molecular size on electron spin relaxation rates of nitroxyl radicals in glassy solvents between 100 and 300 K, Mol. Phys, 2007, 105, 2137-2151.

29. Perras FA, Reinig RR, Slowing II, Sadow AD and Pruski M, Effects of Biradical Deuteration on the Performance of DNP: Towards Better Performing Polarizing Agents, Phys. Chem. Chem. Phys, 2015, 18, 65-69. [PubMed: 26619055]

30. Sauvée C, Casano G, Abel S, Rockenbauer A, Akhmetzyanov D, Karoui H, Siri D, Aussenac F, Maas W, Weber RT, Prisner TF, Rosay M, Tordo P and Ouari O, Tailoring of Polarizing Agents in the bTurea Series for Cross-Effect Dynamic Nuclear Polarization in Aqueous Media, Chem. - A Eur. J, 2016, 22, 5598-5606. 
31. Mance D, Gast P, Huber M, Baldus M and Ivanov KL, The magnetic field dependence of crosseffect dynamic nuclear polarization under magic angle spinning, J. Chem. Phys, 2015, 142, 234201. [PubMed: 26093552]

32. Mentink-Vigier F, Paul S, Lee D, Feintuch A, Hediger S, Vega S and De Paëpe G, Nuclear depolarization and absolute sensitivity in magic-angle spinning cross effect dynamic nuclear polarization, Phys. Chem. Chem. Phys, 2015, 17, 21824-21836. [PubMed: 26235749]

33. Mentink-Vigier F, Vega S and De Paëpe G, Fast and accurate MAS-DNP simulations of large spin ensembles, Phys. Chem. Chem. Phys, 2017, 19, 3506-3522. [PubMed: 28093594]

34. Mentink-Vigier F, Marin-Montesinos I, Jagtap AP, Halbritter T, van Tol J, Hediger S, Lee D, Sigurdsson ST and De Paëpe G, Computationally Assisted Design of Polarizing Agents for Dynamic Nuclear Polarization Enhanced NMR: The AsymPol Family, J. Am. Chem. Soc, 2018, 140, 11013-11019. [PubMed: 30095255]

35. Mentink-Vigier F, Mathies G, Liu Y, Barra A-L, Caporini MA, Lee D, Hediger S, Griffin RG and De Paëpe G, Efficient cross-effect dynamic nuclear polarization without depolarization in highresolution MAS NMR, Chem. Sci, 2017, 8, 8150-8163. [PubMed: 29619170]

36. Perras FA, Sadow A and Pruski M, In Silico Design of DNP Polarizing Agents: Can Current Dinitroxides Be Improved?, ChemPhysChem, 2017, 18, 2279-2287. [PubMed: 28599086]

37. Hassinen T and Peräkylä M, New energy terms for reduced protein models implemented in an offlattice force field, J. Comput. Chem, 2001, 22, 1229-1242.

38. Clark M, Cramer RD and Van Opdenbosch N, Validation of the general purpose tripos 5.2 force field, J. Comput. Chem, 1989, 10, 982-1012.

39. Neese F, The ORCA program system, Wiley Interdiscip. Rev. Comput. Mol. Sci, 2012, 2, 73-78.

40. Schäfer A, Horn H and Ahlrichs R, Fully optimized contracted Gaussian basis sets for atoms Li to Kr, J. Chem. Phys, 1992, 97, 2571-2577.

41. Weigend $F$ and Ahlrichs R, Balanced basis sets of split valence, triple zeta valence and quadruple zeta valence quality for $\mathrm{H}$ to Rn: Design and assessment of accuracy, Phys. Chem. Chem. Phys, 2005, 7, 3297. [PubMed: 16240044]

42. Weigend F, Accurate Coulomb-fitting basis sets for H to Rn, Phys. Chem. Chem. Phys, 2006, 8, 1057. [PubMed: 16633586]

43. Becke AD, Density-functional thermochemistry. I. The effect of the exchange-only gradient correction, J. Chem. Phys, 1992, 96, 2155-2160.

44. Stephens PJ, Devlin FJ, Chabalowski CF and Frisch MJ, Ab Initio Calculation of Vibrational Absorption and Circular Dichroism Spectra Using Density Functional Force Fields, J. Phys. Chem, 1994, 98, 11623-11627.

45. Becke AD, Density-functional thermochemistry. III. The role of exact exchange, J. Chem. Phys, 1993, 98, 5648-5652.

46. Sinnecker S and Neese F, Spin-Spin Contributions to the Zero-Field Splitting Tensor in Organic Triplets, Carbenes and BiradicalsA Density Functional and Ab Initio Study, J. Phys. Chem. A, 2006, 110, 12267-12275. [PubMed: 17078624]

47. Du JL, Eaton GR and Eaton SS, Temperature, Orientation, and Solvent Dependence of Electron Spin-Lattice Relaxation Rates for Nitroxyl Radicals in Glassy Solvents and Doped Solids, J. Magn. Reson. Ser. A, 1995, 115, 213-221.

48. Bordignon E, in eMagRes, John Wiley \& Sons, Ltd, Chichester, UK, 2017, vol. 6, pp. 235-254.

49. Dubroca T, Smith AN, Pike KJ, Froud S, Wylde R, Trociewitz B, McKay J, Mentink-Vigier F, van Tol J, Wi S, Brey W, Long JR, Frydman L and Hill S, A quasi-optical and corrugated waveguide microwave transmission system for simultaneous dynamic nuclear polarization NMR on two separate 14.1 T spectrometers, J. Magn. Reson, , DOI:10.1016/j.jmr.2018.01.015.

50. Rosay M, Tometich L, Pawsey S and Bader R, Solid-state dynamic nuclear polarization at 263 GHz: spectrometer design and experimental results, Phys. Chem. Chem. Phys, 2010, 12, 5850-60. [PubMed: 20449524]

51. Takahashi H, Fernández-de-Alba C, Lee D, Maurel V, Gambarelli S, Bardet M, Hediger S, Barra A-L and De Paëpe G, Optimization of an absolute sensitivity in a glassy matrix during DNPenhanced multidimensional solid-state NMR experiments., J. Magn. Reson, 2014, 239, 91-9. [PubMed: 24480716] 
52. Hartmann S and Hahn E, Nuclear Double Resonance in the Rotating Frame, Phys. Rev, 1962, 128, 2042-2053.

53. Schaefer J and Stejskal EO, Carbon-13 nuclear magnetic resonance of polymers spinning at the magic angle, J. Am. Chem. Soc, 1976, 98, 1031-1032.

54. Hediger S, Meier BH and Ernst RR, Chem. Phys. Lett, 1995, 240, 449-456.

55. Fung BM, Khitrin a K. and Ermolaev K, An improved broadband decoupling sequence for liquid crystals and solids., J. Magn. Reson, 2000, 142, 97-101. [PubMed: 10617439]

56. Barra AL, Hassan a. K., Janoschka A, Schmidt CL and Schünemann V, Broad-band quasi-optical HF-EPR spectroscopy: Application to the study of the ferrous iron center from a rubredoxin mutant, Appl. Magn. Reson, 2006, 30, 385-397.

57. Neugebauer P and Barra AL, New Cavity Design for Broad-Band Quasi-Optical HF-EPR Spectroscopy, Appl. Magn. Reson, 2010, 37, 833-843.

58. van Tol J, Brunel L-C and Wylde RJ, A quasioptical transient electron spin resonance spectrometer operating at 120 and $240 \mathrm{GHz}$, Rev. Sci. Instrum, 2005, 76, 074101.

59. Morley GW, Brunel L-C and van Tol J, A multifrequency high-field pulsed electron paramagnetic resonance/electron-nuclear double resonance spectrometer, Rev. Sci. Instrum, 2008, 79, 064703. [PubMed: 18601425]

60. Stoll S and Schweiger A, EasySpin, a comprehensive software package for spectral simulation and analysis in EPR., J. Magn. Reson, 2006, 178, 42-55. [PubMed: 16188474]

61. Gafurov M, Lyubenova S, Denysenkov V, Ouari O, Karoui H, Le Moigne F, Tordo P and Prisner TF, EPR Characterization of a Rigid Bis-TEMPO-Bis-Ketal for Dynamic Nuclear Polarization, Appl. Magn. Reson, 2010, 37, 505-514.

62. Mao J, Akhmetzyanov D, Ouari O, Denysenkov V, Corzilius B, Plackmeyer J, Tordo P, Prisner TF and Glaubitz C, Host-Guest Complexes as Water-Soluble High-Performance DNP Polarizing Agents., J. Am. Chem. Soc, , DOI:10.1021/ja409840y.

63. Mentink-Vigier F, Collauto A, Feintuch A, Kaminker I, Tarle V and Goldfarb D, Increasing sensitivity of pulse EPR experiments using echo train detection schemes, J. Magn. Reson, 2013, 236, 117-125. [PubMed: 24121563]

64. Zaremba SK, Good lattice points, discrepancy, and numerical integration, Ann. di Mat. Pura ed Appl. Ser. 4, 1966, 73, 293-317.

65. Conroy H, Molecular Schrödinger Equation. VIII. A New Method for the Evaluation of Multidimensional Integrals, J. Chem. Phys, 1967, 47, 5307-5318.

66. Cheng VB, Suzukawa HH and Wolfsberg M, Investigations of a Nonrandom Numerical-Method for Multidimensional Integration, J. Chem. Phys, 1973, 59, 3992-3999.

67. https://easyspin.org/easyspin/documentation/frames.html, https://easyspin.org/easyspin/ documentation/frames.html.

68. Soetbeer J, Gast P, Walish J, Zhao Y, George C, Yang C, Swager TM, Griffin RG and Mathies G, Conformation of Bis-nitroxide Polarizing Agents by Multi-frequency EPR Spectroscopy, Phys. Chem. Chem. Phys, , DOI:10.1039/C8CP05236K.

69. Hustedt EJ, Smirnov AI, Laub CF, Cobb CE and Beth AH, Molecular distances from dipolar coupled spin-labels: the global analysis of multifrequency continuous wave electron paramagnetic resonance data., Biophys. J, 1997, 72, 1861-77. [PubMed: 9083690]

70. Hu K-N, Song C, Yu H, Swager TM and Griffin RG, High-frequency dynamic nuclear polarization using biradicals: A multifrequency EPR lineshape analysis, J. Chem. Phys, 2008, 128, 052302. [PubMed: 18266419]

71. Dzuba SA, Librational motion of guest spin probe molecules in glassy media, Phys. Lett. A, 1996, 213, 77-84.

72. Kubicki DJ, Rossini AJ, Purea A, Zagdoun A, Ouari O, Tordo P, Engelke F, Lesage A and Emsley L, Amplifying Dynamic Nuclear Polarization of Frozen Solutions by Incorporating Dielectric Particles, J. Am. Chem. Soc, 2014, 136, 15711-15718. [PubMed: 25285480]

73. Hoff DEM, Albert BJ, Saliba EP, Scott FJ, Choi EJ, Mardini M and Barnes AB, Frequency swept microwaves for hyperfine decoupling and time domain dynamic nuclear polarization, Solid State Nucl. Magn. Reson, 2015, 72, 79-89. [PubMed: 26482131] 
74. Salikhov KM, Dzuba SA and Raitsimring AM, The theory of electron spin-echo signal decay resulting from dipole-dipole interactions between paramagnetic centers in solids, J. Magn. Reson, 1981, 42, 255-276.

75. Goldman M, Impurity-Controlled Nuclear Relaxation, Phys. Rev, 1965, 138, A1675-A1681.

76. Epel B, Pöppl A, Manikandan P, Vega S and Goldfarb D, The Effect of Spin Relaxation on ENDOR Spectra Recorded at High Magnetic Fields and Low Temperatures, J. Magn. Reson, 2001, 148, 388-397. [PubMed: 11237646]

77. Mathies G, Caporini MA, Michaelis VK, Liu Y, Hu K-N, Mance D, Zweier JL, Rosay M, Baldus $\mathrm{M}$ and Griffin RG, Efficient Dynamic Nuclear Polarization at $800 \mathrm{MHz} / 527 \mathrm{GHz}$ with TritylNitroxide Biradicals, Angew. Chem. Int. Ed, 2015, 127, 11936-11940. 
(a)<smiles>[R]C1([R])CC2(CC([R])([R])N1[O])OCC1(COC3(CO1)CC([R])([R])N([O-])C([R])([R])C3)CO2</smiles>

$\mathrm{R}=\mathrm{Me}$ (bTbk); Spiro (bCTbK); Spiro-Ph (TEKPol)

(b)<smiles>[R]N(C(=O)N([R2])C1CC([R])([R])N([O-])C([R])([R])C1)C1CC([R])([R])N([O-])C([R])([R])C1</smiles>

$\mathrm{R}=$ spirocyclohexyl, $\mathrm{R}=-\left(\mathrm{CH}_{2} \mathrm{CH}_{2} \mathrm{O}\right) \mathrm{Me}, \mathrm{R}_{1}=$ $\mathrm{H}$ (AMUPol); $\mathrm{R}=$ spirocyclohexyl, $\mathrm{R}_{1}=\mathrm{R}_{2}=\mathrm{H}$ (PyPol); $\mathrm{R}=$ spirocyclohexanolyl, $\mathrm{R}_{1}=\mathrm{R}_{2}=\mathrm{H}$ (bcTol); $\mathrm{X}=\mathrm{C}-\mathrm{OH}, \mathrm{R}=\mathrm{R}_{1}=\mathrm{Me}(\mathrm{bcTol}-\mathrm{M})$

Fig. 1.

Chemical structure of nitroxide biradicals used in this study. (a) bTbK family, (b) bTurea family. 


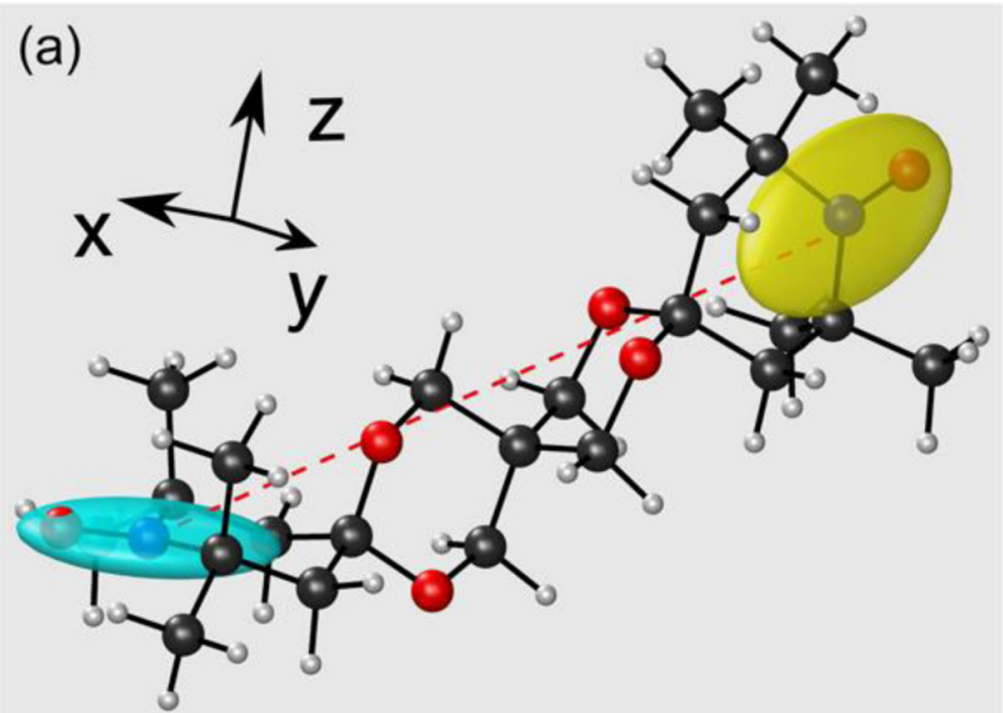

(b)

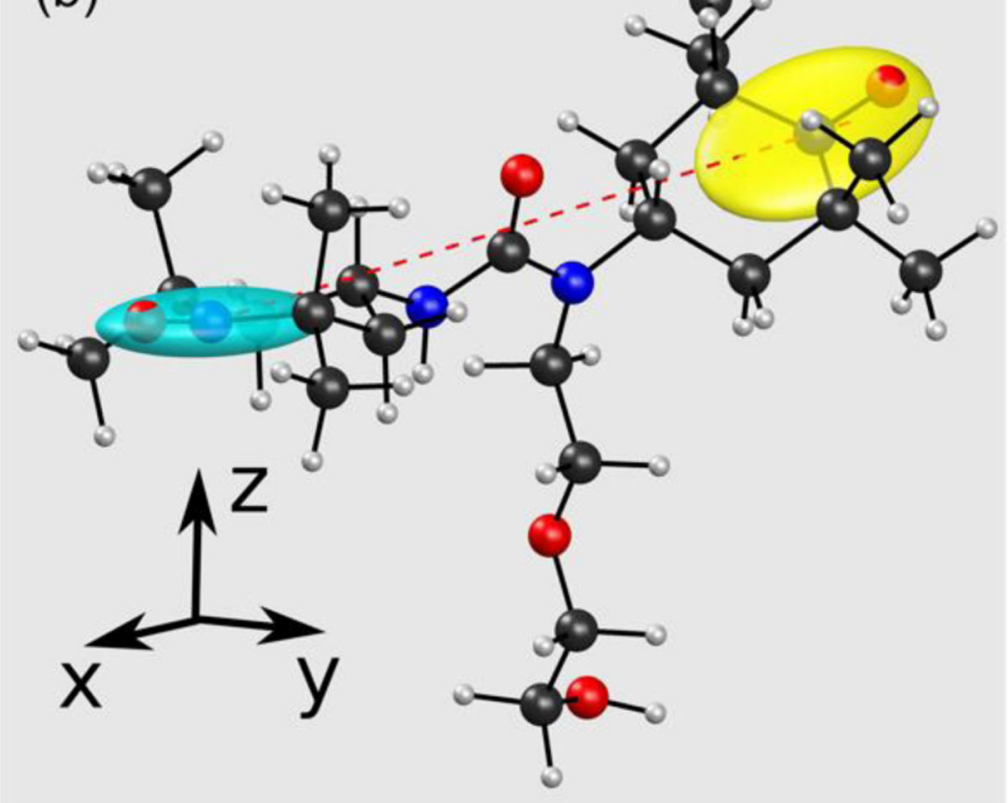

Fig. 2.

Structure of bTbK (a) and modified bTurea with a PEG chain(b), obtained via DFT. The $g$ tensors and dipolar coupling are represented schematically, (the axis length is proportional to the principal axis frame tensor value). In blue and yellow, the $g$-tensor of electron spin a and $\mathrm{b}$, respectively. The colour coding for the atoms is: black corresponds to carbon $(\mathrm{C})$, red to oxygen $(\mathrm{O})$, blue to nitrogen $(\mathrm{N})$, and grey to hydrogen $(\mathrm{H}))$. The structures have been generated with a home-written Matlab code. 


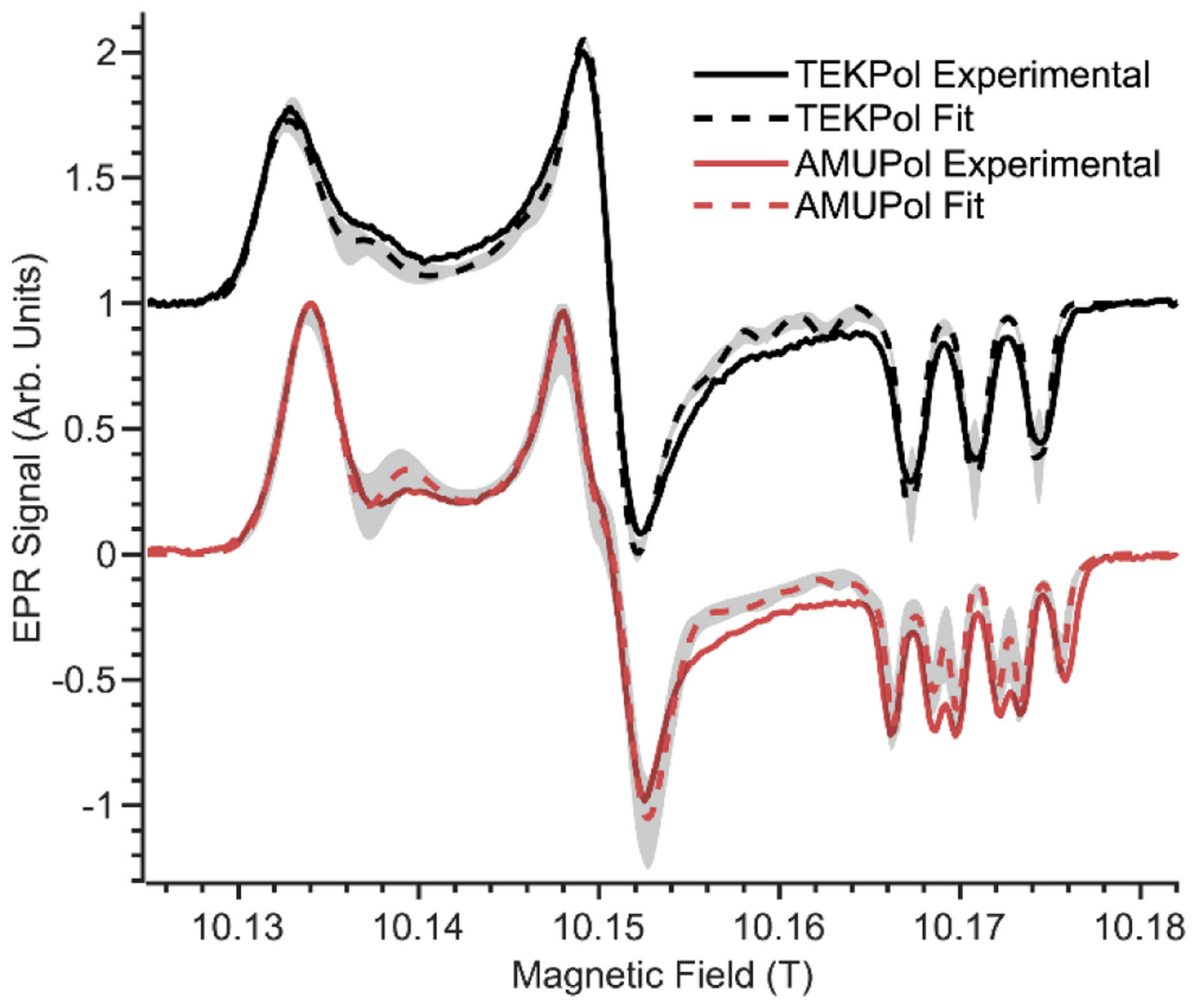

Fig. 3.

High-field EPR spectra of $15 \mathrm{mM}$ TEKPol in $\mathrm{CHCl}_{3} / \mathrm{TBE} / \mathrm{MeOH}-\mathrm{D}_{4}(65 / 35 / 5 \mathrm{v} \%$ ) (black) and $10 \mathrm{mM}$ AMUPol in $\mathrm{D}_{8}$-glycerol/ $\mathrm{D}_{2} \mathrm{O} / \mathrm{H}_{2} \mathrm{O}(60 / 30 / 10 \mathrm{v} \%)+2 \mathrm{M}^{13} \mathrm{C}$-urea (red), both recorded at $100 \mathrm{~K}$ with a microwave frequency of $285 \mathrm{GHz}$. Best fits obtained from the DFT-calculated parameters are shown with black and red dashed lines for TEKPol and AMUPol, respectively. The grey overlays represent the errors reported in Table 1. 


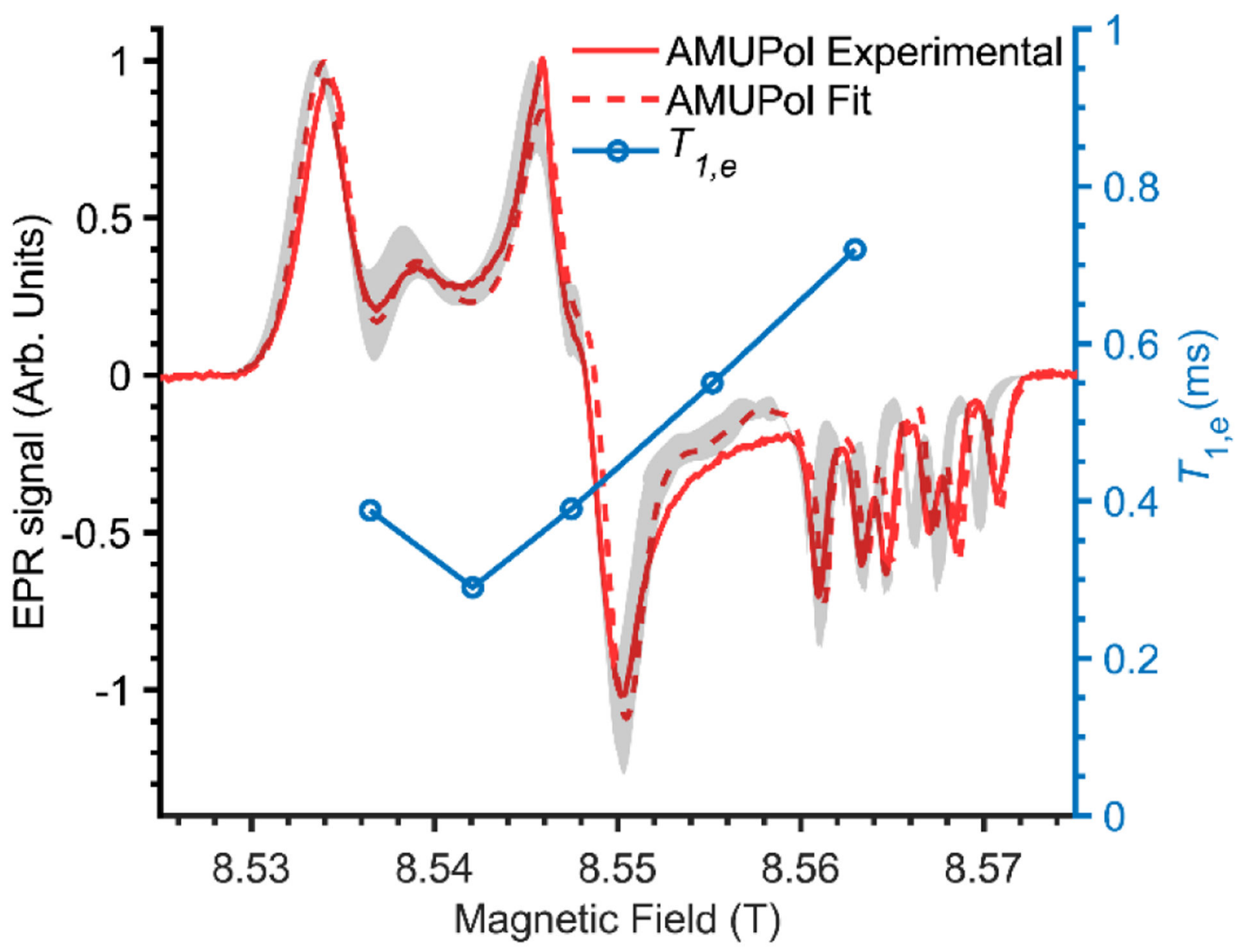

Fig. 4.

High-field EPR spectrum of $10 \mathrm{mM}$ of AMUPol in $\mathrm{D}_{8}$-glycerol/ $\mathrm{D}_{2} \mathrm{O} / \mathrm{H}_{2} \mathrm{O}(60 / 30 / 10 \mathrm{v} \%)$ $+2 \mathrm{M}{ }^{13} \mathrm{C}$-urea, recorded at $100 \mathrm{~K}$, for a microwave frequency of $240 \mathrm{GHz}$. The red curve represents the experimental spectrum and the red dashed line represents the theoretical EPR spectrum obtained with fitted parameters reported table 1 . The blue dots correspond to the measured electron spin-lattice relaxation times, $T_{1 \mathrm{e}}$ (right axis). 

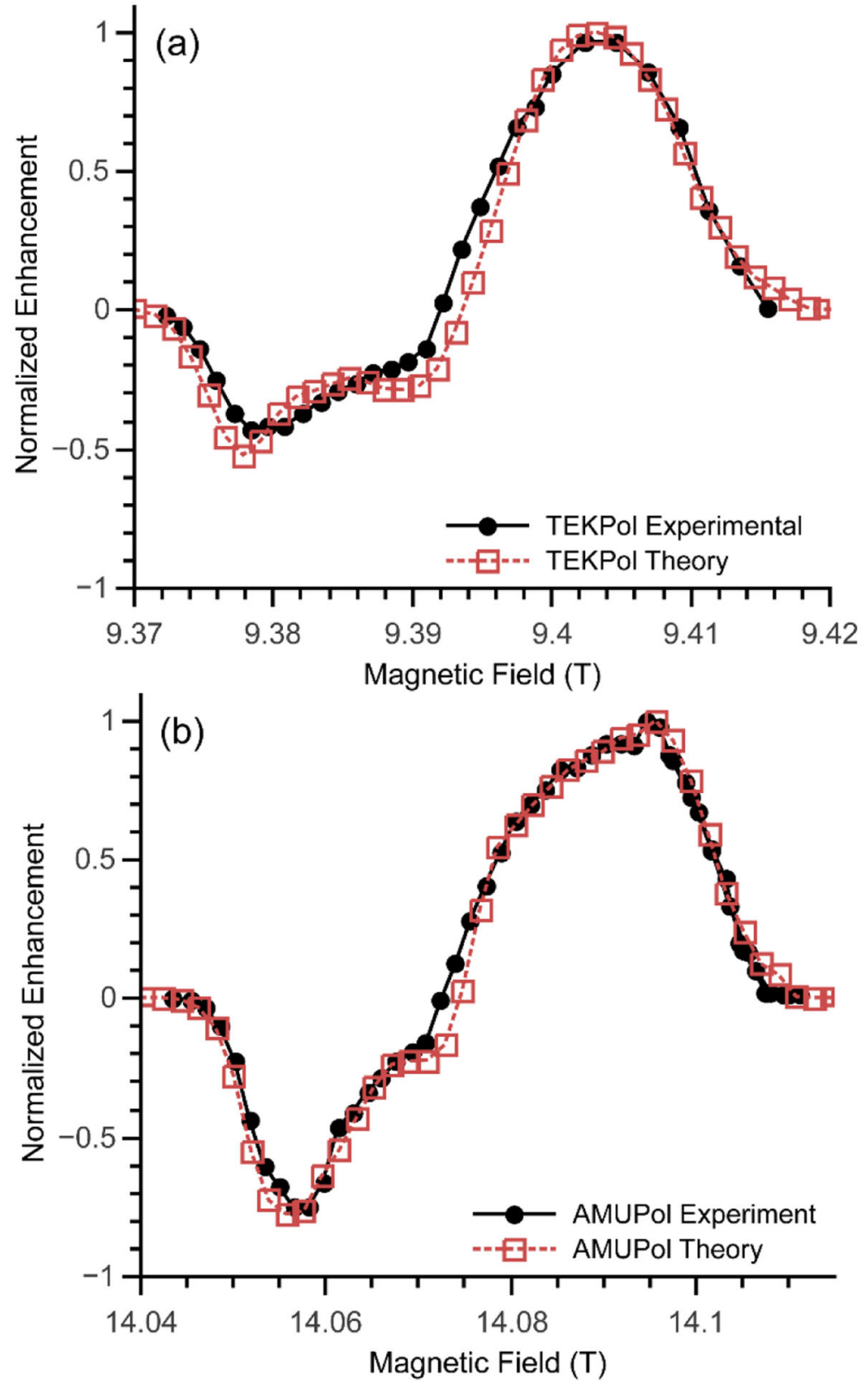

Fig. 5.

Experimental (black circles) and simulated (red squares) MAS-DNP field profiles, i.e. the enhancement $\epsilon_{\mathrm{on} / \mathrm{off}}$ as a function of the magnetic field while keeping the $\mu \mathrm{w}$ irradiation frequency constant, for TEKPol (a) and AMUPol (b) at 9.4 T and 14.1 T, respectively. 


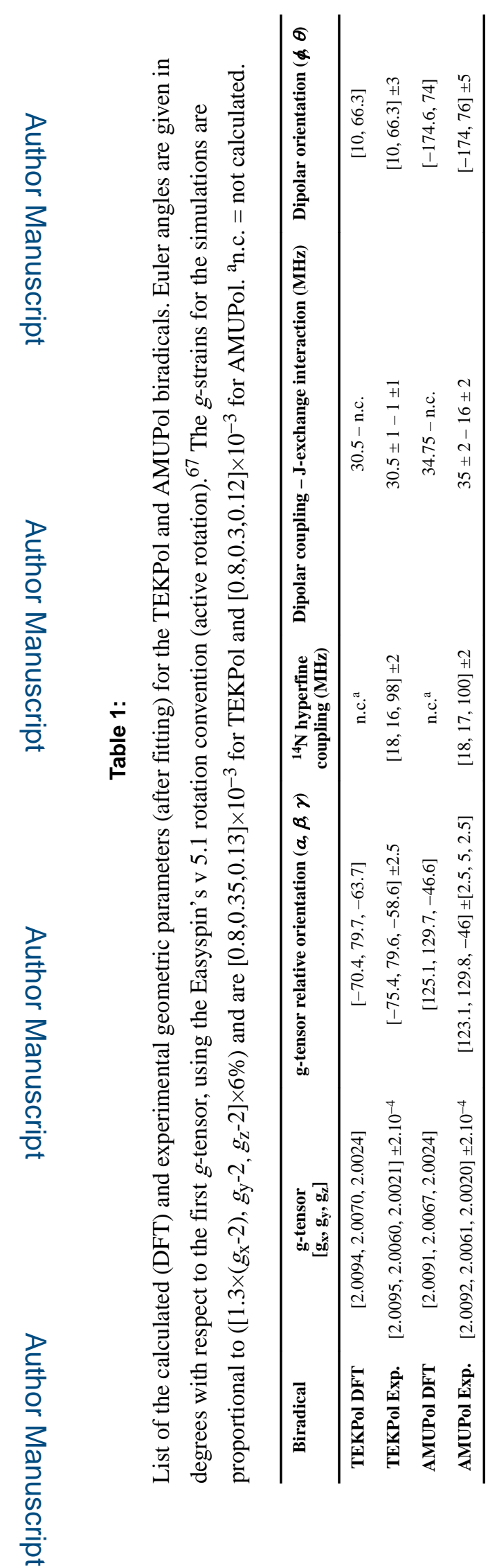

Phys Chem Chem Phys. Author manuscript; available in PMC 2020 January 23. 


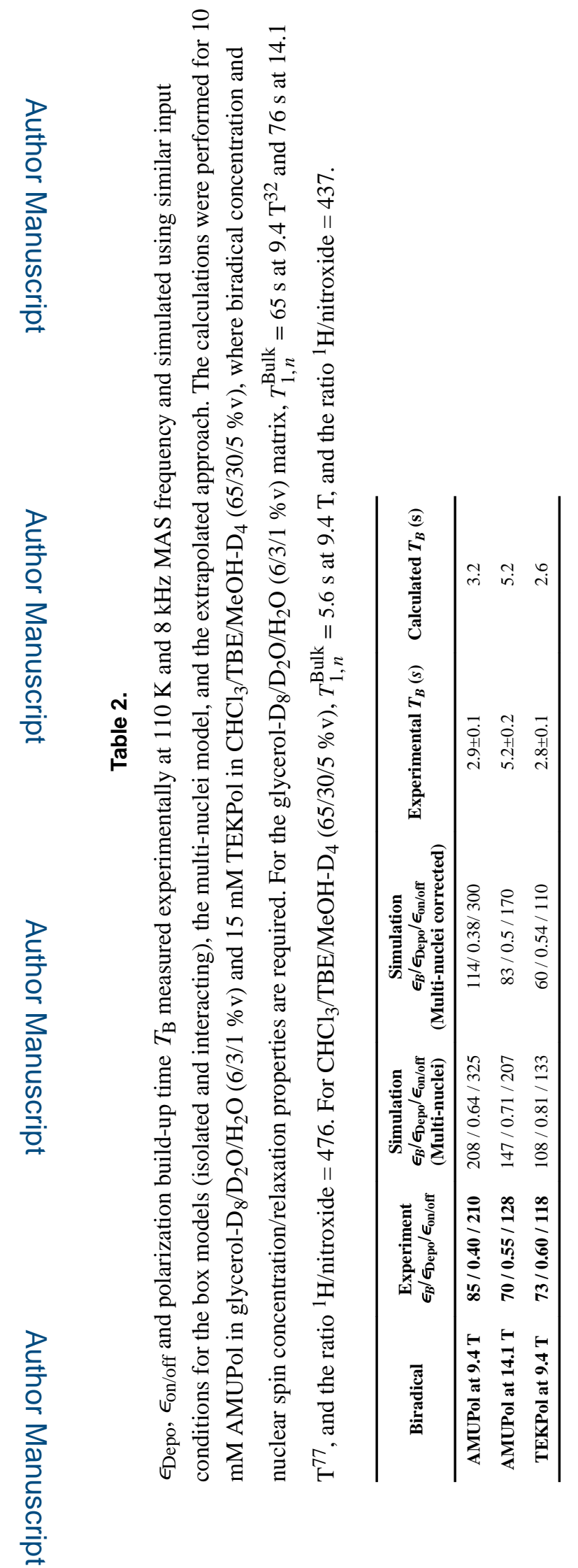

Phys Chem Chem Phys. Author manuscript; available in PMC 2020 January 23. 